\title{
Expression of sphingosine-1 phosphate receptor in rat renal ischemia-reperfusion injury
}

\author{
MASAHIDE MATSUYAMA ${ }^{1}$, KIYOAKI FUNAO $^{2}$, KATSUYUKI KURATSUKURI ${ }^{2}$, \\ TOMOAKI TANAKA ${ }^{2}$, YUTAKA KAWAHITO ${ }^{3}$, HAJIME SANO ${ }^{5}$, JAMEL CHARGUI ${ }^{1}$, \\ JEAN-LOUIS TOURAINE ${ }^{1}$, NORIO YOSHIMURA ${ }^{4}$ and RIKIO YOSHIMURA ${ }^{2}$
}

\begin{abstract}
${ }^{1}$ Department of Transplantation and Clinical Immunology, Claude Bernard University of Lyon and Lyon Hospitals, 69437 Lyon Cedex 3, France; ${ }^{2}$ Department of Urology, Osaka City University Graduate School of Medicine, Osaka 545-8585; Departments of ${ }^{3}$ Inflammation and Immunology, and ${ }^{4}$ Transplantation and Regenerative Surgery, Graduate School of Medical Science, Kyoto Prefectural University of Medicine, Kyoto 602-0841; ${ }^{5}$ Department of Internal Medicine, Hyogo College of Medicine, Hyogo 663-8501, Japan
\end{abstract}

Received October 27, 2009; Accepted December 28, 2009

DOI: 10.3892/mmr_00000245

\begin{abstract}
Sphingosine-1 phosphate receptor (S1PR) has come to the fore as a mediator of extracellular signaling through its interaction with G-protein-coupled receptors, which results in the induction of peripheral T-cell depletion. The mechanisms involved in renal ischemia-reperfusion (I/R) injury are complex, but appear to involve the early participation of bone marrow-derived cells, such as T lymphocytes. In this study, we investigated the expression of SIPR in a rat model of renal $\mathrm{I} / \mathrm{R}$ injury. By means of a laparotomy, the right kidney was harvested and the left renal artery and vein were clamped. The kidney was reperfused after $90 \mathrm{~min}$ of ischemia, and rats were sacrificed at $0,3,6,12$ and $24 \mathrm{~h}$ after reperfusion. S1PR expression was analyzed by immunohistochemistry, and was observed only in endothelial cells of the normal kidneys. From 0 to $3 \mathrm{~h}$ after reperfusion, S1PR expression gradually became stronger in endothelial cells, reaching its peak intensity at $3 \mathrm{~h}$ after reperfusion. Twelve hours after reperfusion, necrosis had extended throughout the ischemic kidney, and nearly all the tubular epithelial cells had been destroyed. From 3 to $12 \mathrm{~h}$ after reperfusion, S1PR expression gradually weakened. At $24 \mathrm{~h}$ after reperfusion, levels of S1PR expression had almost reached those of the normal kidneys. In conclusion, S1PR was found to be expressed in a rat model of renal I/R injury. Several hours after achieving the maximum level of S1PR expression, the maximum level of renal I/R injury was observed. These results suggest a relationship between S1PR and renal $\mathrm{I} / \mathrm{R}$ injury.
\end{abstract}

Correspondence to: Dr Rikio Yoshimura, Osaka City University Graduate School of Medicine, 1-4-3 Asahimachi, Abeno-ku, Osaka 545-8585, Japan

E-mail: jasmin@med.osaka-cu.ac.jp

Key words: sphingosine-1 phosphate receptor, renal ischemiareperfusion injury, acute tubular necrosis

\section{Introduction}

Renal ischemia-reperfusion (I/R) injury, an invariable consequence of renal transplantation, is a clinically significant problem involving the onset of acute tubular necrosis (ATN) when the transplantation includes a long ischemic interval or when using a kidney from a cardiac arrest donor. The longer the ischemic interval, the higher the incidence rate of ATN. It is therefore clinically important to identify methods of reducing renal I/R injury (1).

The identification of mediators of the I/R injury cascade (2) has generated new target sites. Through these, it is possible to abrogate the effect of $\mathrm{I} / \mathrm{R}$ injury using anti-neutrophil preparations (3), free radical scavengers $(4,5)$ and monoclonal antibodies to block adhesion molecules and the inflammatory cytokine cascade (6-8). The mechanisms involved in renal I/R injury are complex, but appear to involve the early participation of bone marrow-derived cells, as T lymphocytes have been shown to participate in its pathogenesis. Sphingosine-1 phosphate receptor (S1PR) has come to the fore as a mediator of extracellular signaling through its interaction with G-protein-coupled receptors, which results in the induction of peripheral T-cell depletion (9).

Several studies have found that the administration of a non-selective S1PR agonist reduces injury resulting from renal I/R (10-13). However, there have been no studies addressing the relationship between S1PR expression and renal I/R injury. In the present study, we investigated this relationship in a rat model of renal I/R injury.

\section{Materials and methods}

Ischemia-reperfusion model. Male Lewis rats (270-320 g) were subjected to laparotomy under pentobarbital sodium anesthesia. The right kidney was harvested and the left renal artery and vein were clamped with a hemostasis clip for $90 \mathrm{~min}$. The clip was subsequently removed to permit reperfusion, and the abdomen was closed during I/R. The left kidneys 

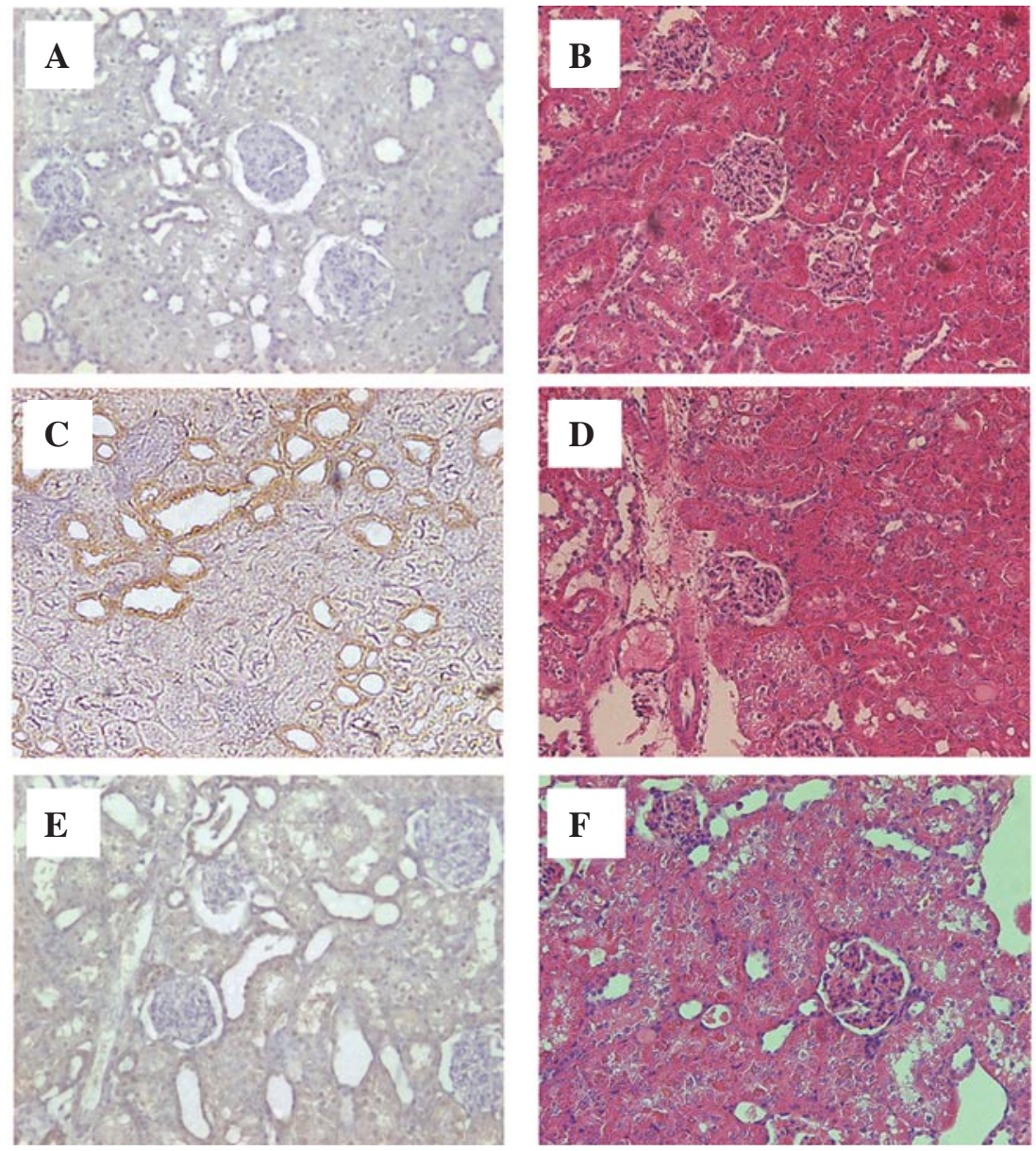

Figure 1. Representative S1PR expression and H\&E staining. A and B show the normal kidney before ischemia. S1PR expression was most intense in endothelial cells at $3 \mathrm{~h}$ after reperfusion (C). Six hours after reperfusion, slight destruction of the tubular epithelial cells was noted (D). Twelve hours after reperfusion, necrosis extended throughout the ischemic kidney (F), while $12 \mathrm{~h}$ after reperfusion, S1PR expression gradually became weaker in endothelial cells (E). A, C and E, immunohistochemistry; B,D and F, H\&E staining.

were reperfused. The rats were sacrificed at $0,3,6,12$ and $24 \mathrm{~h}$ after reperfusion, then the kidneys were harvested for immuno-histochemistry. All procedures involving animals were conducted according to the ethical guidelines for animal experimentation of Osaka City University.

Immunohistochemical staining. Samples of ischemic and non-ischemic kidney tissue were fixed in $10 \%$ buffered formalin for $24 \mathrm{~h}$ for immunohistochemical staining. Staining was performed using the Vectastatin avidin-biotin peroxidase complex kit (Vector Laboratories, Burlingame, CA, USA). Kidney tissues sectioned onto microscope slides were deparaffinized, then the slides were immersed for $45 \mathrm{~min}$ in $0.3 \%$ peroxide in methanol to deplete endogenous peroxidase activity. Non-specific binding sites were saturated with $0.2 \%$ bovine serum albumin and normal rabbit serum diluted 1:66.7 in PBS for $20 \mathrm{~min}$. Primary antibodies against rabbit polyclonal to EDG1 (Abcam, Cambridge, UK), a lysophospholipid receptor which binds sphingosine-1 phosphate, and control normal serum (Vector Laboratories) were used at a dilution of 1:50 and applied to the tissue sections. Sections were then incubated in a humidified chamber at room temperature for $30 \mathrm{~min}$, and subsequently washed with PBS for $10 \mathrm{~min}$. Biotinylated goat anti-rabbit IgG (Vector Laboratories) was applied to the sections, followed by incubation at room temperature for $30 \mathrm{~min}$. After washing with PBS for $10 \mathrm{~min}$, the slides were incubated with avidin DH-biotinylated peroxidase (Vector Laboratories) for 45 min. Finally, color was developed by immersion in a peroxidase substrate solution containing $0.02 \%$ peroxide, 3,3' diaminobenzine tetrahydrochloride, $0.04 \%$ nickel chloride and $0.01 \%$ hydrogen peroxide in $0.05 \mathrm{M}$ Tris- $\mathrm{HCl}, \mathrm{pH}$ 7.2, for 2-7 min.

Analysis of acute tubular necrosis and SIPR expression. For the quantification of ATN, the degree of ATN was graded on a scale of 0-3 by two blinded observers, defined as no necrosis, mild, moderate or severe necrosis. Necrosis, capillary congestion, interstitial edema, casts, destruction and flat and extended areas of tubular epithelial cells were also assessed. Similarly, S1PR immunostainings were graded on a scale of 0-4 according to the intensity of immunostaining, with grade 4 being the maximum. Quantification of ATN and S1PR expression was conducted by the same two pathologists throughout the study.

Statistical analysis. Results are presented as the mean \pm SD. Analyses of data were carried out using analysis of variance (ANOVA) (14). 


\section{Results}

$H \& E$ staining and immunohistochemistry of S1PR. S1PR expression was only observed in endothelial cells of the normal kidneys (Fig. 1A). H\&E staining showed normal architecture of the kidney before ischemia (Fig. 1B). From 0 to $3 \mathrm{~h}$ after reperfusion, S1PR expression gradually became stronger in endothelial cells. S1PR expression was most intense in endothelial cells at $3 \mathrm{~h}$ after reperfusion (Fig. 1C). Six hours after reperfusion, the internal spaces of the tubular epithelial cells were expanded, and slight destruction of the cells was noted (Fig. 1D). Twelve hours after reperfusion, necrosis extended throughout the ischemic kidney and nearly all the tubular epithelial cells had been destroyed (Fig. 1F). However, from 3 to $12 \mathrm{~h}$ after reperfusion, S1PR expression gradually became weaker in endothelial cells (Fig. 1E, $12 \mathrm{~h}$ after reperfusion). At $24 \mathrm{~h}$ after reperfusion, levels of S1PR expression almost reached those of the normal kidneys.

Statistical analysis of SIPR expression and acute tubular necrosis. As shown in Table I, S1PR expression scores were significantly higher at 3 and $6 \mathrm{~h}$ than at 0,12 and $24 \mathrm{~h}$ after reperfusion. ATN scores gradually increased with time after reperfusion (Table I).

\section{Discussion}

Renal transplantation is a viable therapeutic approach for patients with end-stage renal disease. However, renal $\mathrm{I} / \mathrm{R}$ injury, which is an invariable consequence of renal transplantation resulting from aortic cross-clamping and resuscitation after systemic hypotension, is a clinically significant problem. Recent studies of I/R injury have focused on the function of neutrophils, the action mechanisms of inflammatory cytokines, tissue factors, intercellular adhesion molecule-1, oxygen-free radicals, vascular plugging, edema and other complications (15).

It has been accepted that organ dysfunction and multi-organ failure following I/R injury is due not to one specific pathway, but is rather mediated by various pathophysiologic processes. The role of neutrophils, lymphocytes, cytokine secretion and endothelial cell adhesion molecules in the pathogenesis of $\mathrm{I} / \mathrm{R}$ injury has been well described (10). While early studies mainly focused on the participation of neutrophils as mediators of I/R injury, recent studies have also demonstrated the importance of $\mathrm{T}$ lymphocyte involvement.

Several studies have found that the non-selective S1PR agonist FTY-720 has a protective effect in rat renal $I / R$ injury (10). FTY-720 is an analogue of sphingosine and acts on the sphingosine receptors, of which there are five. S1PR is required for thymocytes to leave the thymus and for $\mathrm{T}$ and B lymphocytes to leave the lymph nodes (11). FTY-720 binds to the group of G-protein-coupled S1PRs. Awad et al applied FTY-720 and a selective S1PR agonist (SEW2871) in a mouse renal I/R injury model (32 min ischemia and $24 \mathrm{~h}$ reperfusion). Treatment with FTY-720 and SEW2871 resulted in improved histological appearance and a decrease in serum creatinine, vascular permeability and neutrophil infiltration (9). Lien et al reported that SEW2871 improved renal function with a reduction in serum creatinine levels and a significant
Table I. Statistical analysis of S1PR expression and ATN scores.

\begin{tabular}{ccc}
\hline $\begin{array}{c}\text { Time after } \\
\text { reperfusion }(\mathrm{h})\end{array}$ & $\begin{array}{c}\text { S1PR expression } \\
\text { score }(\mathrm{n}=30)\end{array}$ & $\begin{array}{c}\text { ATN score } \\
(\mathrm{n}=30)\end{array}$ \\
\hline Before ischemia & $0.6 \pm 0.5$ & None \\
0 & $0.7 \pm 0.5$ & $1.6 \pm 0.7$ \\
3 & $2.6 \pm 0.8^{\mathrm{a}}$ & $2.4 \pm 0.4$ \\
6 & $2.0 \pm 0.7^{\mathrm{a}}$ & $3.1 \pm 0.7$ \\
12 & $1.2 \pm 0.7$ & $3.2 \pm 0.5$ \\
24 & $0.9 \pm 0.7$ & $3.4 \pm 0.6$ \\
\hline
\end{tabular}

To quantify S1PR expression and ATN, the degree of S1PR expression and ATN was graded on a scale of 0-4 by two blinded observers. Data are presented as the mean \pm SD. Analyses of data were carried out using the analysis of variance (ANOVA). S1PR expression scores were significantly higher at 3 and $6 \mathrm{~h}$ than at 0,12 and $24 \mathrm{~h}$ after reperfusion. ATN scores gradually increased with time after reperfusion. ${ }^{\mathrm{a}} \mathrm{P}<0.01$.

reduction in ATN scores $24 \mathrm{~h}$ after ischemia in a mouse renal I/R injury model, and that SEW2871 ameliorated renal I/R injury by inhibiting lymphocyte regression and reducing proinflammatory molecules (13).

During the process of $\mathrm{I} / \mathrm{R}$ injury, inflammatory reactions are activated and inflammatory cytokines, such as tumor necrosis factor- $\alpha$ and interleukin-1 $\beta$, as well as arachidonic acid metabolites, such as thromboxanes and prostaglandins, are released (16). The conversion of arachidonic acid to thromboxanes and prostaglandins is catalyzed by cyclooxygenase (COX)-2 (17).

Takeyoshi et al found that peroral administration of FK3311 (1 mg/kg), a COX-2 inhibitor, reduced the degree of neutrophilic leukocyte invasion, tissue destruction and thromboxane $\mathrm{B}_{2}$ at $6 \mathrm{~h}$ after reperfusion in a canine 60-min renal warm $\mathrm{I} / \mathrm{R}$ injury model (18). They also reported that the 2-day survival rate was significantly higher upon peroral administration of FK3311 (1 mg/kg) in the COX-2 inhibitor group than in the control inhibitor group in a canine 15-min lung warm I/R injury model (19). In a previous study, we too found COX-2 to be induced in rat renal $\mathrm{I} / \mathrm{R}$ injury using immunohistochemistry (20).

The adipose-derived plasma protein adiponectin (APN) has various protective effects on cardiovascular disease. Ikeda et al reported that APN is required for full COX-2 induction by $\mathrm{I} / \mathrm{R}$ injury in the heart in vivo. In rat neonatal cardiac myocytes, APN-induced COX-2 expression was reduced by treatment with a sphingosine kinase- 1 inhibitor or siRNA-targeting sphingosine kinase-1. Treatment with a S1PR antagonist also diminished COX-2 expression in response to APN stimulation (21). These reports support the relationship between S1PR and COX-2 in I/R injury.

In this study, S1PR was expressed in endothelial cells, reaching maximum intensity $3 \mathrm{~h}$ after I/R injury. From 12 to $24 \mathrm{~h}$ after I/R injury, maximum tissue damage was observed. These results suggest that S1PR plays an important role in renal I/R injury, particularly in I/R-induced ATN. 


\section{References}

1. Matsuyama M and Yoshimura R: Prospects of antisense treatment to alleviate renal ischemia-reperfusion injury. Expert Opin Biol Ther 4: 1931-1937, 2004.

2. Massberg S and Messmer K: The nature of ischemia/reperfusion injury. Transplant Proc 30: 4217-4223, 1998.

3. Paller MS: Effect of neutrophil depletion on ischemic renal injury in the rat. J Lab Clin Med 113: 379-386, 1989.

4. Morpurgo E, Cadrobbi R, Morpurgo M, et al: Protective effect of superoxide dismutase and polyethylene glycol-linked superoxide dismutase against renal warm ischemia/reperfusion injury. Transplantation 62: 1221-1223, 1996.

5. Hansson R, Jonsson O, Lundstam S, Pettersson S, Scherstén T and Waldenström J: Kidney protection by pre-treatment with free radical scavengers and allopurinol: renal function at recirculation after warm ischemia in rabbits. Clin Sci 71: 245-251, 1986.

6. Singbartl K, Green SA and Ley K: Blocking P-selectin protects from ischemia/reperfusion-induced acute renal failure. FASEB J 14: 48-54, 2000.

7. Dragun D, Tullius SG, Park JK, et al: ICAM-1 antisense oligodesoxynucleotides prevent reperfusion injury and enhance immediate graft function in renal transplantation. Kidney Int 54: 590-602, 1998.

8. Kelly KJ, Williams WW Jr, Colvin RB and Bonventre JV: Antibody to intercellular adhesion molecule 1 protects the kidney against ischemic injury. Proc Natl Acad Sci USA 91: 812-816, 1994.

9. Awad AS, Ye H, Huang L, et al: Selective sphingosine-1 phosphate-1 (S1P1) receptor activation reduces ischemia-reperfusion injury in mouse kidney. Am J Physiol Renal Physiol 290: 1516-1524, 2006.

10. Troncoso P, Ortiz M, Martinez L and Kahan BD: FTY 720 prevents ischemic reperfusion damage in rat kidneys. Transplant Proc 33: 857-859, 2001.
11. Solez K, Morel-Maroger L and Staer JD: The morphology of 'acute tubular necrosis' in man: analysis of 57 renal biopsies and a comparison with the glycerol model. Medicine 58: 362-376, 1979.

12. Martin X, Da Silva M, Virieux SR, et al: Protective effect of an anti-LFA 1 monoclonal antibody (odulimomab) on renal damage due to ischemia and kidney autotransplantation. Transplant Proc 32: 481, 2000.

13. Lien YH, Yong KC, Cho C, Igarashi S and Lai LW: S1P(1)selective agonist, SEW2871, ameliorates ischemic acute renal failure. Kidney Int 69: 1601-1608, 2006.

14. Fitzgerald SM and Flinn S: Evaluating research studies using the analysis of variance (ANOVA): issues and interpretations. $\mathrm{J}$ Hand Ther 13: 56-60, 2000.

15. Matsuyama M, Yoshimura R, Akioka K, et al: Tissue factor antisense oligonucleotides prevent renal ischemia-reperfusion injury. Transplantation 76: 786-791, 2003.

16. Naka Y, Roy DK, Smerling AJ, et al: Inhaled nitric oxide fails to confer the pulmonary protection provided by distal stimulation of the nitric oxide pathway at the level of cyclic guanosine monophosphate. J Thorac Cardiovasc Surg 110: 1434-1440, 1995.

17. Chang SW, Westcott JY, Pickett WC, Murphy RC and Voelkel NF: Endotoxin-induced lung injury in rats: role of eicosanoids. Appl Physiol 66: 2407-2418, 1989.

18. Takeyoshi I, Sunose Y, Iwazaki S, et al: The effect of a selective cyclooxygenase- 2 inhibitor in extended liver resection with ischemia in dogs. J Surg Res 100: 25-31, 2001.

19. Sunose Y, Takeyoshi I, Tsutsumi H, et al: Effects of FK3311 on pulmonary ischemia-reperfusion injury in a canine model. J Surg Res 95: 167-173, 2001.

20. Matsuyama M, Yoshimura R, Hase T, Kawahito Y, Sano H and Nakatani T: Study of cyclooxygenase-2 in renal ischemiareperfusion injury. Transplant Proc 37: 370-372, 2005

21. Ikeda Y, Ohashi K, Shibata R, et al: Cyclooxygenase-2 induction by adiponectin is regulated by a sphingosine kinase-1-dependent mechanism in cardiac myocytes. FEBS Lett 582: 1147-1150, 2008. 